\title{
Performance analysis of a two-stage evaporative cooler
}

\author{
Mohammad Jaafarian* and Mohammad Ehsan Kazemian \\ Department of Mechanical Engineering, Bam Higher Education Complex, P.O. Box 76615-314, Bam, Iran
}

Received: 13 September 2016 / Accepted: 16 March 2017

\begin{abstract}
In the present study, a mathematical model of a two-stage evaporative cooling (TSEC) system is presented, which consisted of two direct evaporative coolers and a heat exchanger. In this system, the temperature of the inlet air into evaporative pads decreases through indirect heat exchange with the outlet air stream from the conditioned space, using an unmixed heat exchanger. The outlet air from the conditioned space is also cooled down, prior to cooling the inlet air, through a second evaporation process. The governing equations of the energy and mass are presented and solved simultaneously. The numerical results are then compared with the experimental data reported in the literature to establish confidence in the model. The sensitivity of the performance of the system to the temperature and humidity of the ambient air, efficiency of the direct evaporative pads and overall heat transfer coefficient of the heat exchanger were calculated. The results are discussed to find the parameters with more significant effects on the performance of the system. The sensitivity analysis reveals that further improvements to the performance of the system is possible through increasing of the overall heat transfer within the indirect heat exchanger and increasing of the direct evaporative cooling efficiency.
\end{abstract}

Keywords: evaporative cooling / air conditioning / air humidity / energy saving

\section{Introduction}

Mechanical vapor compression (MVC) and evaporative cooling systems are used in dwelling applications. Although MVC systems can provide lower temperatures than evaporative coolers and are capable to operate in hot and humid conditions, they consume more electrical power than evaporative coolers. Furthermore, most of the working fluids used in MVC systems are harmful for environment, while evaporative cooling systems use water, which is environmentally benign. Furthermore, evaporative cooling systems have lower capital, maintenance and operational costs than MVC systems, which, in turn, make them more attractive economically. So, the interest in evaporative cooling systems is globally on the rise [1,2].

An evaporative cooling system works based on the difference between the wet and dry bulb temperatures of the ambient air. Therefore, the efficiency of these systems in cooling of the air decreases in humid climate, where the difference between the wet and dry bulb temperatures decreases. This has motivated the researchers to look for new options to increase the efficiency of the evaporative cooling systems in various ambient conditions such as humid and hot climates. Sheng and Agwu Nnanna [2] studied the direct evaporative coolers experimentally. They investigated the

\footnotetext{
* e-mail: jaafarian_mohammad@bam.ac.ir
}

effect of frontal air velocity in evaporative pad, the temperature of the inlet air and water on the efficiency of a direct cooling system. They showed that the efficiency of the evaporative pads decreases with the increasing of the frontal velocity, inlet air temperature and inlet water temperature. El-Dessouky et al. [1] proposed an indirect/ direct evaporative cooling system (IEC/DEC), in which the hot and dry inlet air is first cooled down in an indirect evaporative cooling system (IEC), by the cooled water and then it goes through the direct evaporative cooling (DEC) pads. They showed that, in the assessed conditions, the efficiencies of the IEC and DEC systems are about 20-40\% and $63-93 \%$, respectively, while the combination of IEC and DEC systems can improve the efficiency of the system by up to $120 \%$. Therefore, the cooling efficiency of the stand-alone, IEC and DEC units is lower than 1. On the other hand, the cooling efficiency of the combined system may be greater than 1 . The efficiency here is defined as the ratio of the air temperature drop in system to the difference between wet and dry bulb temperature of ambient air. It is worth noting that, since the dry bulb temperature of the outlet air, in IEC/ DEC systems, is lower than the wet bulb temperature of the ambient air, an efficiency of more than 1 is also possible. Fouda and Melikyan [3] present a mathematical model for the heat and mass transfer in direct evaporative pads. Mass and latent heat of evaporated water are contemplated as mass and heat source in mass and energy equations. They show that there is a good agreement between proposed 


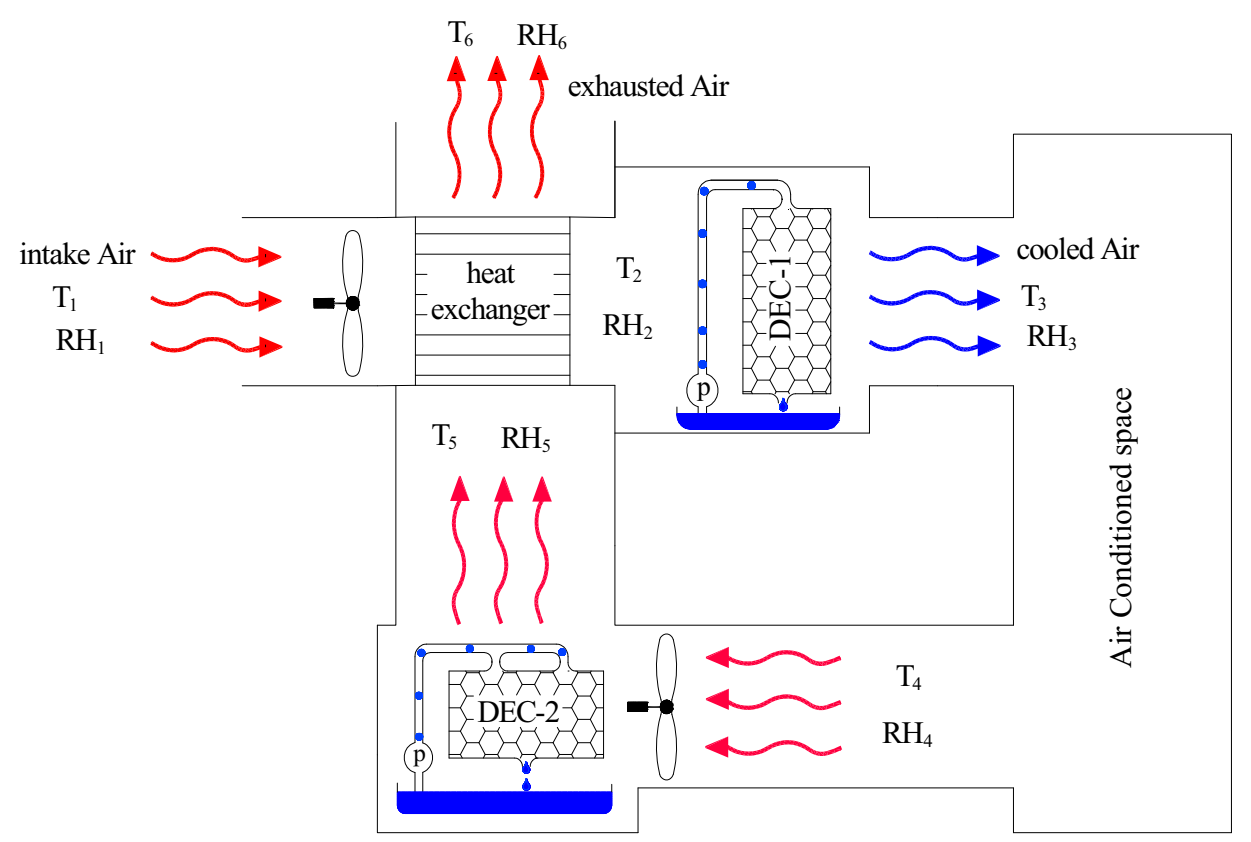

Fig. 1. Schematic representation of the two-stage evaporative cooler developed by Jain [7]. The process consisted of two direct evaporation coolers and on unmixed heat exchanger.

mathematical model and experimental results. Bruno [4] studied counter flow indirect evaporative cooler and demonstrated that temperatures of the outlet air could reach to the ambient dew point temperature. Dew point temperature is considerably lower than the wet bulb temperature, which is the minimum achievable temperature with conventional direct evaporative cooling systems. Lee et al. [5] studied the compactness of regenerative evaporative coolers by three different configurations: flat plate, corrugated plat and finned channel type. A regenerative evaporative cooler is a kind of indirect evaporative cooler which can decrease the temperature to dew point temperature of ambient air. They showed that the finned channel configuration has the most compact and the lightest structure among the three configurations considered. Lee and Lee [6] used a counter flow fin in regenerative evaporative coolers. They investigated the cooling performance using numerical methods. They showed that an extraction ratio of 0.3 can result in the best cooling performance of their assessed system. The extraction ratio in their system is defined as the ratio of mass flow rate in wet channel to dry channel. Jain [7] designed and manufactured a two stage evaporative cooler (TSEC) to cool humid air. This system mainly consisted of two direct evaporative coolers and an unmixed heat exchanger. He showed that this evaporative cooling system can decrease the temperature of the inlet air to wet bulb temperature. However, the efficiency of this system has not been investigated in detail yet. Therefore, the principle objective of the present study is to develop and validate a mathematical model, enabling the assessment of the efficiency of this system. The paper also aims to assess the effect of both the environmental conditions and physical characteristics of the system on the performance of the system with the view to increase its cooling performance.

\section{Description of two-stage evaporative cooler}

Schematic representation of the two-stage evaporative cooler (TSEC) developed by Jain [7] is shown in Figure 1. This system comprises two evaporative coolers and an indirect heat exchanger. Air goes through the wetted pad in the first direct evaporative cooler (DEC-1), where its dry bulb temperature decreases while it is humidified. This is an adiabatic humidification or isenthalpic cooling process [3] and is shown schematically by lines $2-3$ in psychometric chart, shown in Figure 2. The cooled air, in this stage, is then supplied into the house for cooling purposes, where its temperature and humidity increase. This process is shown schematically by lines $3-4$ in Figure 2 . The outlet air from the house is humid but it is not saturated; therefore, by the second direct evaporative cooler (DEC-2), its dry bulb temperature decreases to near its wet bulb temperature, while its humidity increases. This is also an adiabatic humidification process and is shown schematically by $4-5$ in Figure 2. Finally, the outlet air from DEC-2 is used in an unmixed heat exchanger to cool down the inlet air into the DEC-1. In this stage the air temperature increases while its specific humidity does not change. This process is shown schematically by lines $5-6$. The exhaust air from heat exchanger is then evacuated far from the inlet air.

\section{Methodology}

The main assumptions used in the simulation of the system are as follows:

- the thermo-physical properties of the air remain unchanged during the process, despite the change in its temperature and humidity; 


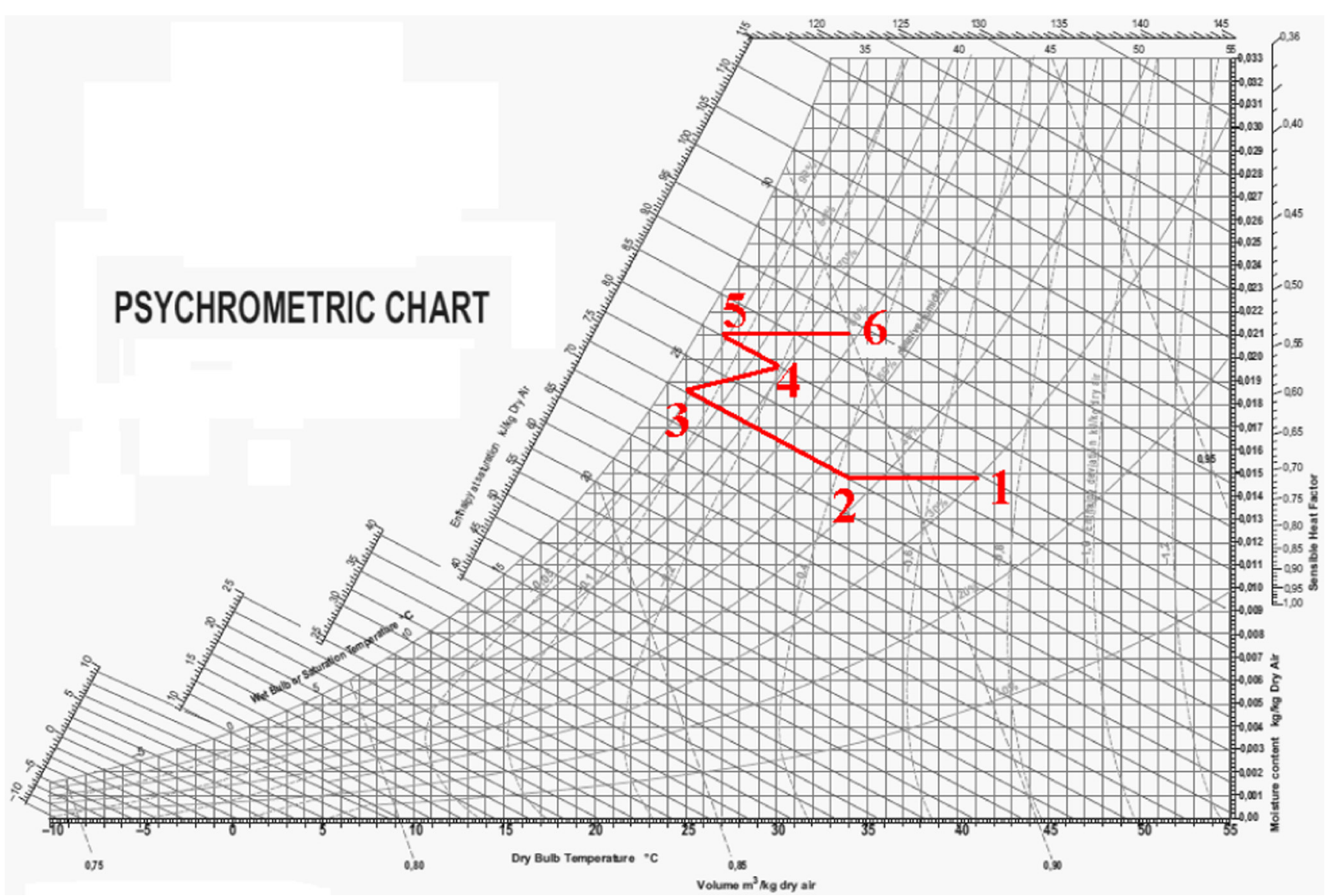

Fig. 2. Schematic representation of the process path of Jain's two-stage evaporative cooling [7] shown on psychometric chart.

- streams of cold and hot fluids do not mix while passing through the heat exchanger;

- the evaporative pads are wetted fully and uniformly;

- Lewis number is equal to $1(L e=1)$, hence $h_{c} / h_{m}=c_{p}[8]$. In this equation, $h_{c}$ and $h_{m}$ are the convective heat and mass transfer coefficients, respectively, and $c_{p}$ is the specific heat of air;

- the walls are completely isolated, so that the convective and radiative heat losses from walls of the device are ignored;

- temperature distribution is only considered in the direction of the airflow;

- physical properties of evaporative pads and mass flow rate in DEC-1 and DEC-2 are analogous to each other.

The analysis of heat exchanger is done by effectivenessNTU method [9]. With regard to Figure 1, the overall heat transfer, $q$, between the hot and cold streams in the heat exchanger is given by:

$$
q=\varepsilon C_{\min }\left(T_{1}-T_{5}\right)
$$

In this equation, $\varepsilon$ is the effectiveness of heat exchanger, $T_{1}$ and $T_{5}$ are the temperature of ambient air and the temperature of outlet air from DEC-2, respectively, $C_{\min }$ is the heat capacity of the minimum fluid, which is defined as:

$$
C_{\min }=c_{p, a} \dot{m}_{a, i}, \quad i=1 \quad \text { or } \quad 2
$$

In this equation, $c_{p, a}$ is specific heat capacity of air.

As shown in Figure 1, $T_{2}$ is the inlet air temperature to DEC-1 and evaluated by:

$$
T_{2}=T_{1}-\frac{q}{c_{p, a} \dot{m}_{a, 1}}
$$

where $\dot{m}_{a, 1}$ is gas flow rate in DEC-1.

As shown in Figure $1, T_{6}$ is the exhausted air temperature from heat exchanger, and calculated by following equation:

$$
T_{6}=T_{5}+\frac{q}{c_{p, a} \dot{m}_{a, 2}}
$$

where $\dot{m}_{a, 2}$ is gas flow rate in DEC-2. In heat exchanger, two fluids are unmixed and effectiveness is defined as follows [10]:

$$
\varepsilon=1-\exp \left(\frac{\exp \left(-N T U^{0.78} \cdot C\right)-1}{C \cdot N T U^{-0.22}}\right)
$$

That

$$
C=\frac{C_{\min }}{C_{\max }} ; \quad C=c_{p, a} \dot{m} ; \quad N T U=\frac{U A}{C_{\min }}
$$




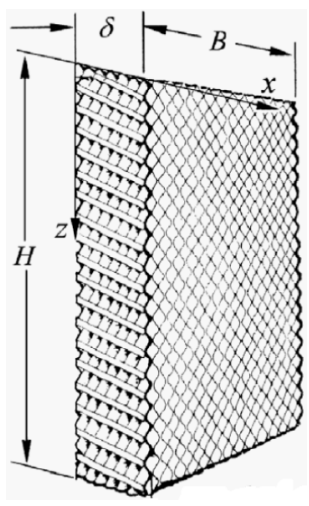

Fig. 3. Configuration of an evaporative pad.

In these equations $A$ is heat transfer area, $\dot{m}$ is the gas flow rate, $U$ is the overall heat transfer coefficient and is given by [10]:

$$
\frac{1}{U A}=\frac{1}{h_{h} A}+R_{f, h}+\frac{\beta}{k A}+R_{f, c}+\frac{1}{h_{c} A}
$$

where $h_{h}$ and $h_{c}$ are the convective heat transfer coefficients in the hot and cold streams, respectively. $R_{f, h}$ and $R_{f, c}$ are the fouling resistance on hot and cold surface, respectively, $k$ and $\beta$ are conductivity and the thickness of heat exchanger plate respectively.

While air goes through the evaporative pad, its temperature decreases, whereas its humidity increases. The change in the temperature of the air is given by [8]:

$$
T_{a}(x)=T_{w}+\left(T_{i}-T_{w}\right) \exp \left(-\frac{h_{c} \xi B H}{\dot{m}_{a} c_{p, a}} x\right)
$$

As shown in Figure 3, $x$ is distance from the beginning of pad, $B$ and $H$ are dimensions of pad, $T_{a}(x)$ is the air temperature at point $x, T_{i}$ is the inlet air temperature, $T_{w}$ is the water temperature inside the pad, $h_{c}$ is the convective heat transfer coefficient and $\xi$ is defined as the pore surface coefficient per unit volume of pad, depending on the configuration of pad module, and $\dot{m}_{a}$ is the mass flow rate of the air in DEC-1 or DEC-2 and is given by:

$$
\dot{m}_{a}=\rho_{a} B H V_{a}
$$
of air.
Change of specific humidity of the air along the $x$ direction is calculated by [8]:

$$
\omega_{a}(x)=\omega_{s}-\frac{c_{p, a}}{\gamma}\left(T_{i}-T_{w}\right) \exp \left(-\frac{h_{c} \xi B H}{\dot{m}_{a} c_{p}} x\right)
$$

Here $\omega_{a}(x)$ is specific humidity of the air in the pad; $\omega_{s}$ is the specific humidity of the inlet saturated air and $\gamma$ is the latent heat of water evaporation.

The exhausted air temperature from the air-conditioned space is calculated as follows:

$$
T_{4}=T_{3}+\frac{\dot{Q}_{s}}{\dot{m}_{a, 1} c_{p, a}}
$$

where $\dot{Q}_{s}$ is the sensible heat of room space in unit of volume and time and $\dot{m}_{a, 1}$ is the mass flow rate in DEC- 1 . The exhausted air humidity from the air-conditioned space is given by:

$$
\omega_{4}=\omega_{3}+\frac{\dot{Q}_{L}}{\dot{m}_{a, 1} r}
$$

where $\dot{Q}_{L}$ is the latent heat of room space in unit of volume and time.

Efficiency of the direct evaporative pad is defined as follows [8]:

$$
\text { see equation (13) below }
$$

To evaluate the efficiency of two-stage evaporative cooler, the following equation was used by Jain in earlier work [8]:

$$
\text { see equation (14) below }
$$

El-Dessouky et al. [1] suggested the following equation: see equation (15) below

The key parameters of the process are presented in Table 1 . The sensitivity of system to the variations of these parameters was also assessed to detect those variables with the greatest influence on the operation of the system.

\section{Model validation}

Performance of the proposed model has been validated through comparison of the predicted outlet air temperature, relative humidity and system efficiency by the model with the experimental data reported by Jain [7] in the same

$$
\begin{gathered}
\eta=\frac{T_{d b} \text { of air entering the pad }-T_{d b} \text { of air leaving the pad }}{\text { Wet bulb depression of air entering the pad }} \times 100 \\
\lambda=\frac{T_{d b} \text { of air entering the system }-T_{d b} \text { of the conditioned air }}{\text { Wet bulb depression of air entering the system } \times \eta} \times 100 \\
\lambda=\frac{T_{d b} \text { of air entering the system }-T_{d b} \text { of the conditioned air }}{\text { Wet bulb depression of air entering the system }} \times 100
\end{gathered}
$$


Table 1. The key parameters for the simulation of twostage evaporative cooler.

\begin{tabular}{|c|c|c|}
\hline Variable & $\begin{array}{l}\text { Reference } \\
\text { operating } \\
\text { conditions [7] }\end{array}$ & $\begin{array}{l}\text { Variation } \\
\text { range }\end{array}$ \\
\hline Inlet air temperature $\left({ }^{\circ} \mathrm{C}\right)$ & 41 & $22-42$ \\
\hline Inlet air relative humidity (\%) & 30 & $10-50$ \\
\hline $\begin{array}{l}\text { Overall heat transfer } \\
\text { coefficient of heat } \\
\text { exchanger }\left(\mathrm{W} \mathrm{m}^{-2}{ }^{\circ} \mathrm{C}^{-1}\right)\end{array}$ & 18 & $15-50$ \\
\hline $\begin{array}{l}\text { Surface of compact heat } \\
\text { exchanger }\left(\mathrm{m}^{2}\right)\end{array}$ & 33 & 33 \\
\hline Mass flow rate $\left(\mathrm{kg} \mathrm{s}^{-1}\right)$ & 2.06 & 2.06 \\
\hline $\begin{array}{l}\text { Effectiveness of the direct } \\
\text { evaporative pad }(\eta)\end{array}$ & 90 & $40-80$ \\
\hline
\end{tabular}

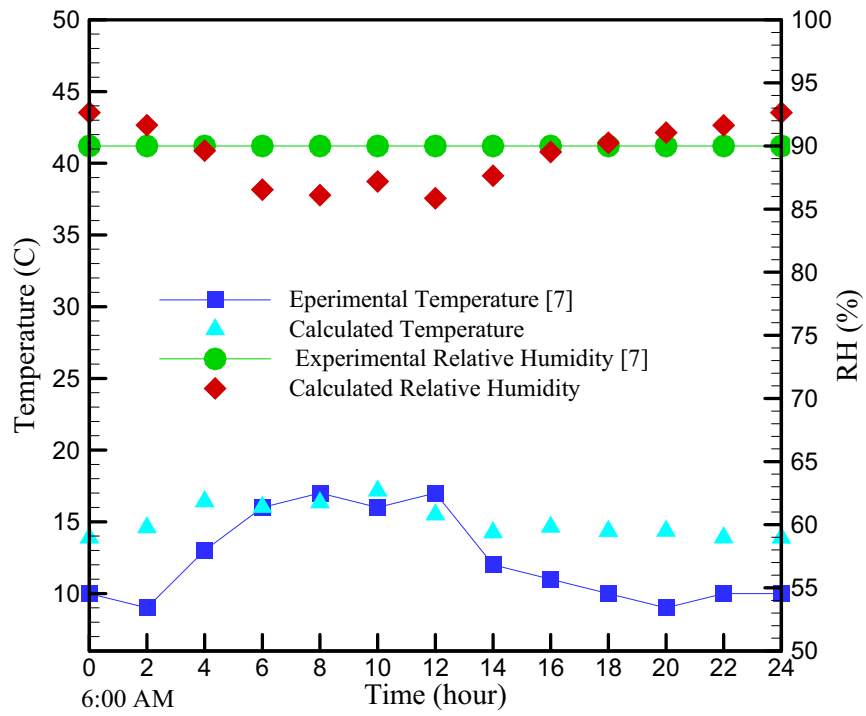

Fig. 4. Comparison of the predicted temperature and humidity by the present model with those measured experimentally by Jain [7].

operating conditions. It is worth noting that the system efficiency has been calculated by equation (14). These comparisons are shown in Figures 4 and 5. As can be seen, a good agreement exists between the model predictions and the experimental data [7] with a deviation of less than $10 \%$ between them, which is mainly due to the simplifying assumptions employed in the model. Hence, the models can be used to further study the system performance.

\section{Results and discussion}

In this section, the sensitivities of the outlet air temperature and overall efficiency of the system to the variations in the inlet air temperature and humidity, the evaporative pad efficiency and the overall heat transfer coefficient of the heat exchanger are investigated.

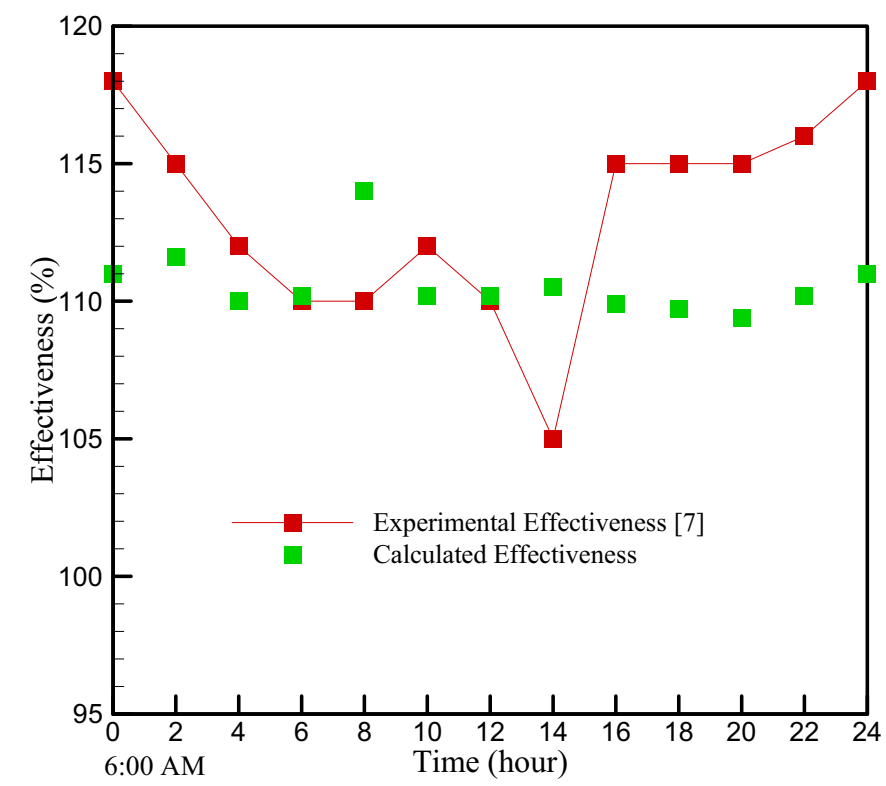

Fig. 5. Comparison of the predicted effectiveness by the present model with those measured experimentally by Jain [7].

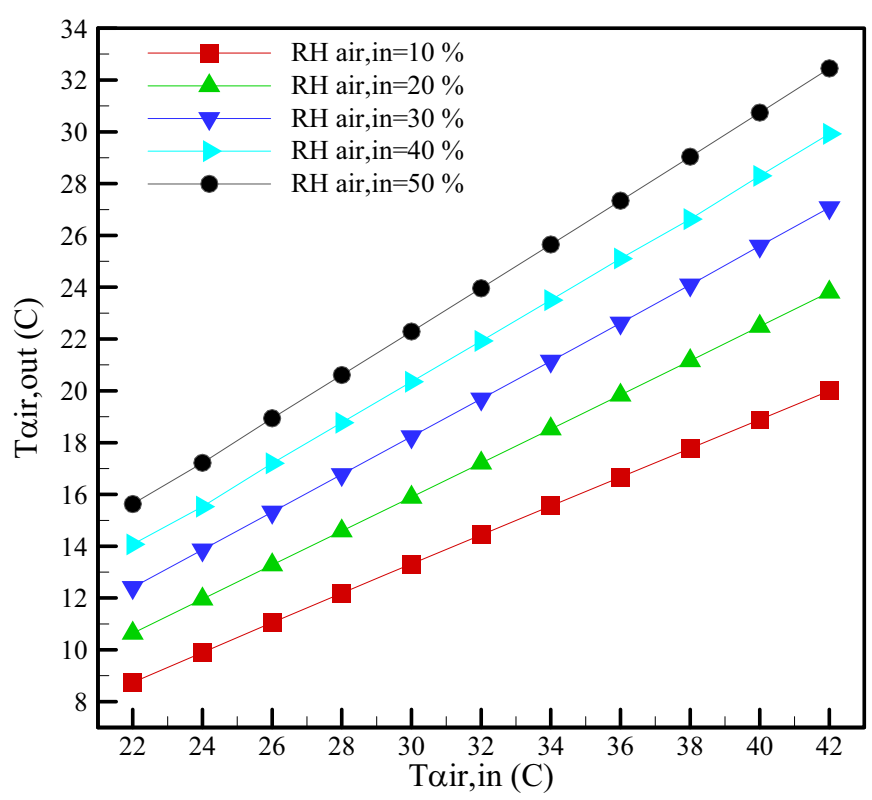

Fig. 6. The calculated sensitivity of the outlet air temperature to variations in the inlet air temperature at different inlet air humidities, for $\eta=90 \%$ and $U=18 \mathrm{~W} \mathrm{~m}^{-2}{ }^{\circ} \mathrm{C}^{-1}$.

\subsection{Sensitivity of the outlet air temperature to the variations in the inlet air temperature at different relative humidities}

The predicted sensitivities of the outlet air temperature, $T_{\text {air.out }}$, to the variations in the inlet air temperature, $T_{\text {air }, i n}$, in different relative humidities of the inlet air, $R H_{\text {air }, i n}$, are presented in Figure 6, for the reference data given in Table 1 . As can be seen, the outlet air temperature increases significantly and almost linearly with inlet air temperature. For example, at $R H_{\text {air }, \text { in }}=10 \%, T_{\text {air,out }}$ increases from $8.7^{\circ} \mathrm{C}$ 


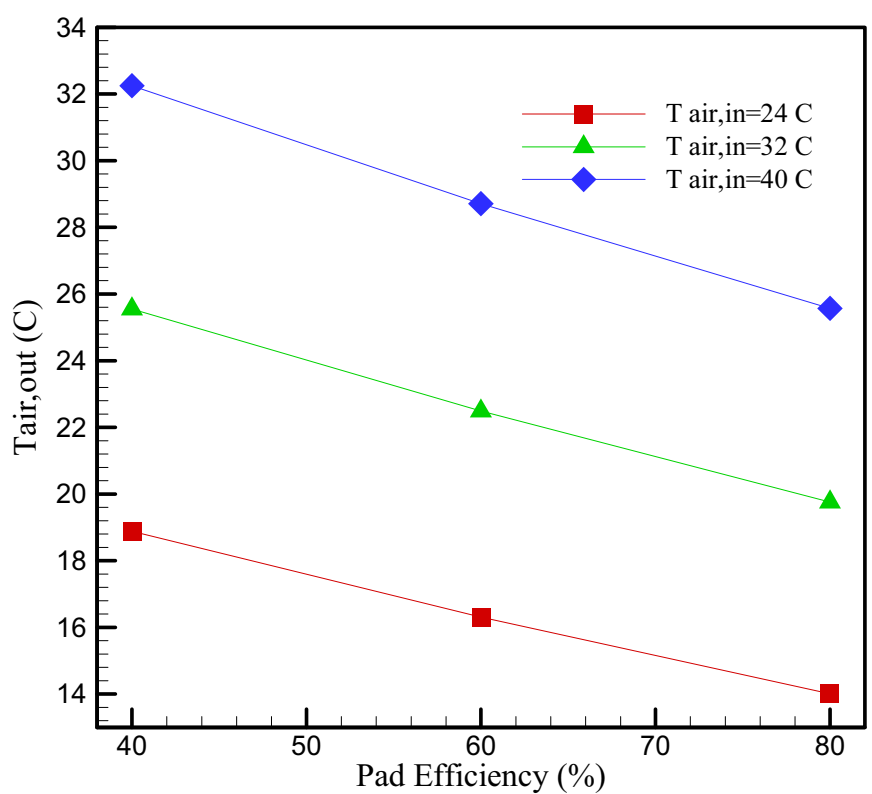

Fig. 7. The calculated sensitivity of the outlet air temperature to variations in the pad efficiency at different inlet air temperatures.

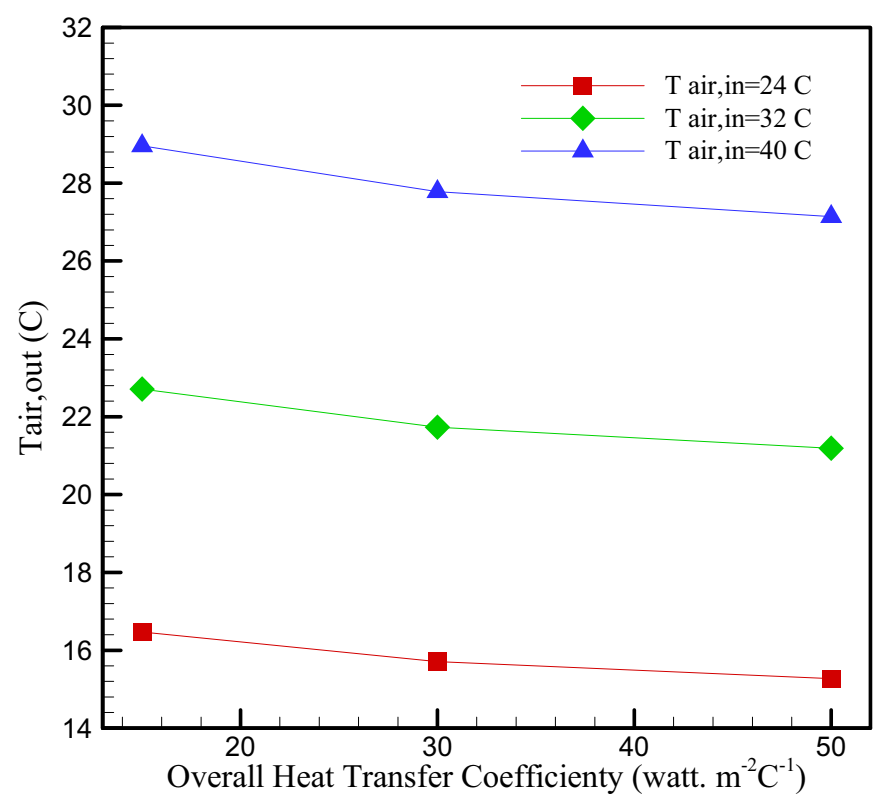

Fig. 8. Calculated sensitivity of outlet air temperature of the system to the overall heat transfer coefficient of heat exchanger at different inlet air temperatures.

Table 2. The calculated sensitivity of the outlet air humidity to variations in the pad efficiency at different inlet air temperatures.

\begin{tabular}{llllllllll}
\hline Pad efficiency (\%) & \multicolumn{3}{c}{40} & \multicolumn{3}{c}{60} & \multicolumn{3}{c}{80} \\
\hline$T_{\text {air }, \text { in }}\left({ }^{\circ} \mathrm{C}\right)$ & 24 & 32 & 40 & 24 & 32 & 40 & 24 & 32 & 40 \\
$R H_{\text {air }, \text { out }}(\%)$ & 47.05 & 46.89 & 46.79 & 62.80 & 62.71 & 61.50 & 79.44 & 79.18 & 78.93 \\
\hline
\end{tabular}

Table 3. Sensitivity of system effectiveness to overall heat transfer coefficient of heat exchanger and pad efficiency.

\begin{tabular}{llllllllll}
\hline Overall heat transfer coefficient, $U\left(\mathrm{~W} \mathrm{~m}^{-2}{ }^{\circ} \mathrm{C}^{-1}\right)$ & & \multicolumn{1}{c}{15} & \multicolumn{3}{c}{35} & & & \multicolumn{2}{c}{50} \\
\hline Pad efficiency, $\eta(\%)$ & 40 & 60 & 80 & 40 & 60 & 80 & 40 & 60 & 80 \\
System effectiveness, $\lambda(\%)$ & 45.3 & 67.9 & 86.4 & 50.0 & 74.0 & 93.7 & 53.5 & 78 & 97.5 \\
\hline
\end{tabular}

at $T_{\text {air,in }}=22^{\circ} \mathrm{C}$ to $20^{\circ} \mathrm{C}$ at $T_{\text {air,in }}=42^{\circ} \mathrm{C}$. This is mainly attributed both to the increasing of the evaporation of water on the pads with increasing of the inlet air temperature and decreasing of the temperature difference within the heat exchanger. Furthermore, this increase is more significant at high values of inlet air temperature than at low ones. For example at $T_{\text {air,in }}=22^{\circ} \mathrm{C}$, an increase in inlet air humidity from $10 \%$ to $50 \%$ leads to $6.9^{\circ} \mathrm{C}$ increase in outlet air temperature, while at $T_{\text {air,in }}=42^{\circ} \mathrm{C}$, this increase in inlet air humidity results in $12.5^{\circ} \mathrm{C}$ increase in outlet air temperature.

\subsection{Sensitivity of the outlet air temperature and rela- tive humidity to the variations in the efficiency of pad}

The calculated sensitivity of the outlet air temperature, $T_{\text {air,out }}$, and relative humidity, $R H_{\text {air,out }}$, of the TSEC to the efficiency of pad at different inlet air temperatures, $T_{a i r, i n}$, for the given data in Table 1, are presented in Figure 7 and Table 2, respectively. As expected, the outlet air temperature decreases and outlet air humidity increases while the efficiency of evaporative pad increases. For example, for $T_{\text {air,in }}=32^{\circ} \mathrm{C}$, as the evaporative pad efficiency increases from $40 \%$ to $80 \%$, the outlet air temperature decreases from $25.55^{\circ} \mathrm{C}$ to $19.76^{\circ} \mathrm{C}$ and the outlet humidity of the system increases from $46.89 \%$ to $79.18 \%$.

In higher pad efficiency, cooling performance of pad increases and difference between wet bulb of inlet air and outlet air temperature decreases, which indicates that outlet air approaches to equilibrium and saturated conditions. Furthermore, at constant pad efficiency, as ambient air temperature increases, outlet air temperature increases and outlet humidity of system remains constant approximately. For example, at $\eta=60 \%$, as ambient air temperature increases from $24^{\circ} \mathrm{C}$ to $40^{\circ} \mathrm{C}$, outlet temperature increases from $16.31^{\circ} \mathrm{C}$ to $28.71^{\circ} \mathrm{C}$, while the humidity 
remains approximately constant at $62 \%$. With attention to equation (13), while pad efficiency is constant, outlet air temperature changes linearly by inlet air temperature.

\subsection{Sensitivity of outlet air temperature to overall heat transfer coefficient of heat exchanger}

The calculated sensitivity of the outlet air temperature of the TSEC, $T_{\text {air,out, }}$ to overall heat transfer coefficient of heat exchanger, $U$, at different inlet air temperatures, $T_{\text {air, in }}$, for the reference case given in Table 1 , is presented in Figure 8. It can be seen that, while the overall heat transfer coefficient of heat exchanger increases the outlet air temperature decreases. For example, for $T_{\text {air }, \text { in }}=32{ }^{\circ} \mathrm{C}$, as overall heat transfer coefficient increases from $15 \mathrm{~W} \mathrm{~m}^{-2}{ }^{\circ} \mathrm{C}^{-1}$ to $50 \mathrm{~W} \mathrm{~m}^{-2}{ }^{\circ} \mathrm{C}^{-1}$ the outlet air temperature decreases from $22.71^{\circ} \mathrm{C}$ to $21.19^{\circ} \mathrm{C}$. This is because that in the heat exchanger, the ambient air is cooled by the return air from the conditioned room. At higher overall heat transfer coefficients, temperature of the inlet air into evaporative pad decreases, which leads to decreasing of the outlet air.

\subsection{Sensitivity of the overall effectiveness to heat transfer coefficient of heat exchanger and pad efficiency}

Table 3 presents the calculated sensitivity of the system effectiveness to the overall heat transfer coefficient of the heat exchanger and efficiency of evaporative pads, for the reference case given in Table 1 .

As it can be seen in Table 1, when overall heat transfer coefficient of heat exchanger is constant, at higher pad efficiencies, the overall effectiveness of the system increases. For example, at $U=35 \mathrm{~W} \mathrm{~m}^{-2}{ }^{\circ} \mathrm{C}^{-1}$ as pad efficiency increases from $40 \%$ to $80 \%$, overall effectiveness increases from $50.0 \%$ to approximately 94\%. With attention to equation (15), while pad efficiency increases, difference between outlet air temperature and wet bulb of ambient air decreases so overall effectiveness increases. While pad efficiency is constant and overall heat transfer coefficient increases, overall effectiveness increases. For example, at $\eta=80 \%$, as overall heat transfer coefficient increases from $15 \mathrm{~W} \mathrm{~m}^{-2}{ }^{\circ} \mathrm{C}^{-1}$ to $50 \mathrm{~W} \mathrm{~m}^{-2}{ }^{\circ} \mathrm{C}^{-1}$, also the overall effectiveness increases from $86.4 \%$ to approximately $97.5 \%$. This is because the increasing of the overall heat transfer coefficient of the heat exchanger results in the increasing of the difference between inlet and outlet air temperature from the heat exchanger. With attention to pad efficiency outlet air temperature decreases in DEC-1. The decrease of the inlet air temperature to DEC-1 leads to the decreasing of the outlet air temperature, which results in increasing of the process overall effectiveness. In the heat exchanger, temperature decreases and specific humidity remains constant. In this situation wet bulb temperature decreases and outlet air temperature from DEC-1 would become less than ambient wet bulb temperature so that this can result in an effectiveness of more than 1.

\section{Conclusion}

This paper presents a mathematical model of a two-stage evaporative cooler. The comparison of the predictions of the model with the experimental data shows a great agreement between them. The sensitivity of the outlet air temperature and overall effectiveness of the system to the pad efficiency, overall heat transfer coefficient of heat exchanger, ambient air temperature and relative humidity have been also assessed. The results show that:

- while ambient air temperature or ambient relative humidity increases, outlet air temperature increases;

- the outlet air temperature decreases with the increase of pad efficiency, while the outlet relative humidity and overall effectiveness increase with it;

- an increase in the overall heat transfer coefficient of heat exchanger decreases the outlet temperature and increases system overall effectiveness;

- the overall effectiveness of system is sensitive to pad efficiency and overall heat transfer coefficient. The effect of pad efficiency is more significant than that of the overall heat transfer coefficient.

\section{Nomenclature}

$A \quad$ heat transfer area $\left(\mathrm{m}^{2}\right)$

$B$ dimension of evaporative pad $(\mathrm{m})$

$c_{p, a} \quad$ specific heat of air $\left(\mathrm{J} \mathrm{kg}^{-1}{ }^{\circ} \mathrm{C}^{-1}\right)$

$H$ dimension of evaporative pad $(\mathrm{m})$

$h_{c} \quad$ convective heat transfer coefficients $\left(\mathrm{W} \mathrm{m}^{-2}{ }^{\circ} \mathrm{C}^{-1}\right)$

$h_{m} \quad$ convective mass transfer coefficients $\left(\mathrm{kg} \mathrm{m}^{-2} \mathrm{~s}^{-1}\right)$

$k \quad$ conductivity of heat exchanger plate $\left(\mathrm{W} \mathrm{m}^{-2}{ }^{\circ} \mathrm{C}^{-1}\right)$

Le $\quad$ Lewis number

$\dot{m}_{a} \quad$ mass flow rate of air $\left(\mathrm{kg} \mathrm{s}^{-1}\right)$

$q \quad$ overall heat transfer (W)

$Q_{L} \quad$ latent heat of room space $\left(\mathrm{W} \mathrm{m}^{-3}\right)$

$\hat{Q}_{s} \quad$ the sensible heat of room space $\left(\mathrm{W} \mathrm{m}^{-3}\right)$

$R_{f, c} \quad$ fouling resistance on cold surface $\left(\mathrm{W}^{-1} \mathrm{~m}^{2}{ }^{\circ} \mathrm{C}\right)$

$R_{f, h}$ fouling resistance on hot surface $\left(\mathrm{W}^{-1} \mathrm{~m}^{2}{ }^{\circ} \mathrm{C}\right)$

$R H$ relative humidity

$T$ temperature $\left({ }^{\circ} \mathrm{C}\right)$

$T_{a}(x)$ air temperature at point $x\left({ }^{\circ} \mathrm{C}\right)$

$T_{d b} \quad$ dry bulb temperature $\left({ }^{\circ} \mathrm{C}\right)$

$T_{i} \quad$ inlet air temperature $\left({ }^{\circ} \mathrm{C}\right)$

$T_{w} \quad$ water temperature inside the pad $\left({ }^{\circ} \mathrm{C}\right)$

$U \quad$ overall heat transfer coefficient $\left(\mathrm{W} \mathrm{m}^{-2}{ }^{\circ} \mathrm{C}^{-1}\right)$

$V_{a} \quad$ air velocity $\left(\mathrm{m} \mathrm{s}^{-1}\right)$

$x \quad$ Cartesian coordinate system (m)

$\beta \quad$ thickness of heat exchanger plate $(\mathrm{m})$

$\gamma \quad$ latent heat of water evaporation $\left(\mathrm{J} \mathrm{kg}^{-1}\right)$

$\varepsilon \quad$ effectiveness of heat exchanger

$\eta \quad$ pad efficiency $(\%)$

$\lambda \quad$ system effectiveness $(\%)$

$\xi \quad$ pore surface coefficient per unit volume of pad $\left(\mathrm{m}^{2} \mathrm{~m}^{-3}\right)$

$\omega_{a}(x)$ specific humidity of the air in the pad $\left(\mathrm{kg} \mathrm{kg}^{-1}\right)$

$\omega_{s} \quad$ specific humidity of the inlet saturated air

\section{References}

[1] H. El-Dessouky, H. Ettouny, A. Al-Zeefari, Performance analysis of two stage evaporative coolers, Chem. Eng. J. 102 (2004) 255-266 
[2] C. Sheng, A.G. Agwu Nnanna, Empirical correlation of cooling efficiency and transport phenomena of direct evaporative cooler, Appl. Therm. Eng. 40 (2012) 48-55

[3] A. Fouda, Z. Melikyan, A simplified model for analysis of heat and mass transfer in a direct evaporative cooler, Appl. Therm. Eng. 31 (2011) 932-936

[4] F. Bruno, On-site experimental testing of a novel dew point evaporative cooler, Energy Build. 43 (2011) 3475-3483

[5] J. Lee, B.S. Choi, D.-Y. Lee, Comparison of configurations for a compact regenerative evaporative cooler, Int. J. Heat Mass Transf. 65 (2013) 192-198
[6] J. Lee, D.-Y. Lee, Experimental study of a counter flow regenerative evaporative cooler with finned channels, Int. J. Heat Mass Transf. 65 (2013) 173-179

[7] D. Jain, Development and testing of two-stage evaporative cooler, Build. Environ. 42 (2007) 2549-2554

[8] J.M. Wu, X. Huang, H. Zhang, Theoretical analysis on heat and mass transfer in a direct evaporative cooler, Appl. Therm. Eng. 29 (2009) 980-984

[9] J.P. Holman Bejan, Heat transfer, 6th ed., McGraw-Hill, New York, 1986

[10] W.M. Kays, A.L. London, Compact heat exchangers, 3rd ed., McGraw-Hill, New York, 1984

Cite this article as: M. Jaafarian, M.E. Kazemian, Performance analysis of a two-stage evaporative cooler, Mechanics \& Industry 18, 403 (2017) 